\title{
Weights and Balances in Ancient Egypt
}

$\mathrm{I}^{\mathrm{N}}$ $\mathrm{N}$ the study of ancient weights there has been a tendency to broaden the application of inference from comparison of different standards, until it has grown from the attempt to trace the origin of later standards to the modern field of research. The main objectives now are the farreaching character of international trade and the common basis of exchange at a very early date and a closer linking up of the derived standards of later, and even present, days with the earliest originals.

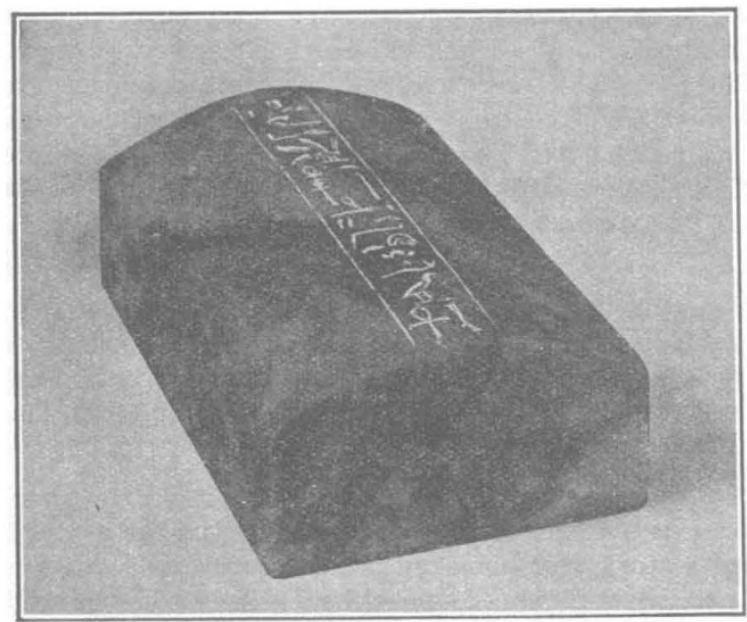

FIG. 1. Green felspar weight of Herfu; value, 100 units Beqa standard (c. 2000 B.C.). (Ưniversity College)

Prof. S. R. K. Glanville, in his Friday evening discourse at the Royal Institution on "Weights and Balances in Ancient Egypt", delivered on November 8,1935 , and now available in printed form, while recognising the wider aims of modern metrological studies, confined himself of set purpose to indicating what we are justified in inferring, from the actual contemporary weights and from the pictorial representations of balances, as to the practice of buying and selling in private and public life throughout the dynastic period in Ancient Egypt.

The pioneer in the study of ancient weights is Sir Flinders Petrie, whose "Inductive Metrology" (1875) is a classic text-book; and by far the largest number of known Egyptian weights were discovered by him. A majority of them, some 3,000 in number, until recently formed a part of the Egyptological collections of University College, London, and a large representative selection is now on loan at the Science Museum, South Kensington. They range from less than 10 grains to more than a quarter of a hundredweight. Over the lower weights the series increases by decimal points of a grain and after that by grains, so that there are very few places in the sequence of the unit weights between 100 and 11,000 grains not represented by a specimen. The shapes vary as do the materials, most, however, being of stone of one kind or another. Petrie suggests that eight standards were current in Egypt from dynastic times, these representing a series of unifications of a much larger number of earlier standards. Two only were indigenous to Egypt, the Beqa (Fig. 1) and the Qedet, the remaining six being traced to various points of origin in the Near Eastern area. The archæological remains of even the pre-dynastic period are of sufficiently diverse character and origin to warrant a conclusion pointing to a volume of early international trade such as this variety of standard implies.

Turning to the balances, there must have been some primitive contrivance from pre-dynastic times. A beam of a balance at University College is made of limestone and may be of pre-dynastic date, but need not be later than the third dynasty (3000 B.c.), for with the tray of numbered weights depicted on the wall of the Third Dynasty tomb of Hesy at Saqqara, two exactly similar objects are shown. With the succeeding dynasty we reach a series of representations of balances, usually of the standard type, showing an improvement as the Old Kingdom develops. The most primitive is from a Fifth Dynasty tomb at Gizeh, in which the beam is a solid arc-shaped piece of wood slung from a joist between two uprights and having at either end what look like pans suspended from a single piece of string. The single string seems to be characteristic of representations of the balance in the Old Kingdom, the cord having a hook at the end. The standard balances, with this single exception, show one upright only, to which the beam was attached. An example of this period, figured in Davies's "Deir-el-Gebrawi", shows the plummet for the first time (Fig. 2). It appears that the string of the plummet is not attached to the upright, as it should be, but hangs from a long board, which in the New Kingdom became a neat tongue, rigidly attached to the beam and moving with it.

One other important representation of the Fifth Dynasty shows the simple beam suspended by a loop held in the hand. This is the only representa. tion of a balance in the Old Kingdom not used for weighing out precious metals. The craftsman weighs the finished object to show that none of 
the precious metal has gone astray. This raises the question of the use of the balance. All representations are in scenes in the tombs of great officials with responsibilities to the Crown, and all depict the exact measurement of precious metals. This fact, together with the evidence of representations of market scenes in which no balances appear and

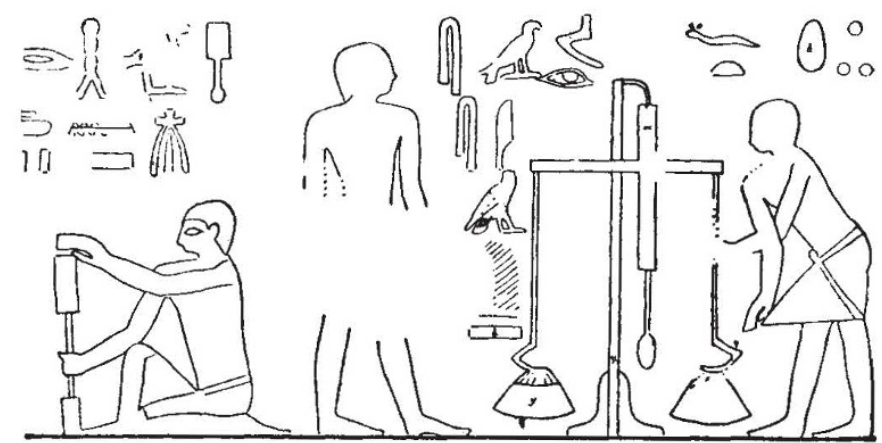

FIG. 2. Old Kingdom balance showing plummet (c. 2500 B.o.). By courtesy of the Egypt Exploration Society.

importation of foreign goods. Although these goods to a great extent were prizes of war, it is highly probable that a large part of the scenes representing the importation of precious metals and manufactured goods show only one half of a picture of organised international trade. This is borne out by references in the Amarna letters to the gifts of gold from Egypt to rulers of western Asia. By this time the term ynt 'to bring', from which the term for gifts is derived, had acquired the meaning 'to buy'. On the other hand, the financial privileges granted to the priesthood indicate that the ruler no longer had a financial monopoly. In the light of these two influences on the economics of the New Kingdom, it is not surprising to find innovations in the detail of weights and balances.

The balance is represented more frequently than ever in tomb paintings and is usually of the standard type; but

exchange is evidently by barter, and the early conception of the land as a single estate belonging to the king, justify the inference that for ordinary business no medium of exchange was in use in the Old Kingdom. The first evidence for the use of metal as a medium of exchange by the man in the street appears in the Eleventh Dynasty in the letters of Kekanekht to his son in Thebes, referring to the renting of land and the purchase of grain, linen and other essential commodities. It is implied that transactions are to be carried out with the aid of some medium of exchange, presumably copper.

With the restoration of Pharaonic control under the Twelfth Dynasty, the estate system under the immediate control of the monarch was again in full swing and the balance, less frequently depicted, is still found weighing gold and silver for official purposes. The best examples indicate the next advance in balance technique in the form in which the single suspender at the end of the beam gives place to a proper pan suspended by four strings looped together through a hole in the beam (Fig. 3).

Though little remains of the period of the domination of the foreigner, the Hyksos kings, in the Seventeenth and Eighteenth Dynasties the legacy of the

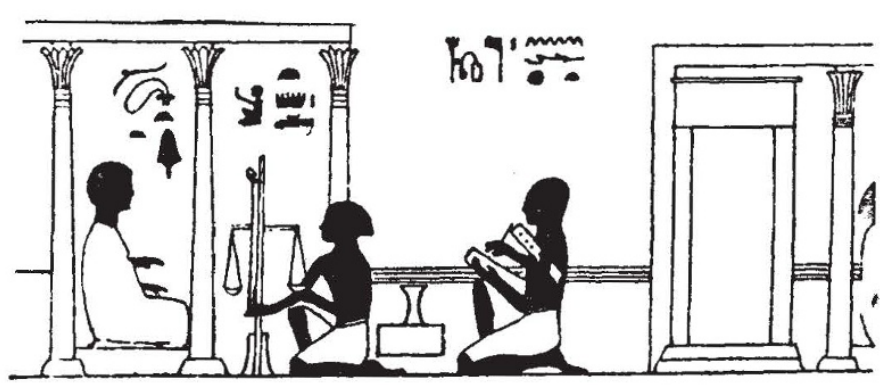

FIG. 3. Middle Kingdom balance with suspension cords (c. 2000 B.o.). By courtesy of the Egypt Exploration Society. foreigner is made plain. Foreign standards show a considerable increase in use; the balance reaches its highest point of efficiency; but far more important are the changes in administration introduced in the early centuries of the new empire. In the height of imperial power no important tomb is without some reference to the at least one example survives of the small hand balance, a beam and two pans now in the Science Museum (c. 1350 в.c.). The paintings show strong stands with carefully joined uprights with metal fittings for strength. Weights change form considerably, and bronze specimens in the form of ox, hippopotamus and gazelle become common, probably as a result of Asiatic influence. The type of balance now continued more or less unchanged until superseded by Roman instruments.

In the Eighteenth and Nineteenth Dynasties the balance continued to be used for weighing out gold to workmen within an official estate, or for the receipt of 'tribute' from foreign countries, or of duties, etc., within the State. The one exception is from a tomb now lost, which depicts the arrival of foreign boats from the Asiatic coast at an Egyptian port and includes representations of two hand balances (Fig. 4). It appears to be the first and only example of the use of the balance for private buying. Other evidence of a different kind, for example, a papyrus of accounts in Cairo, 
points in the same direction; but documents of the Twentieth and Twenty-first Dynasties indicate on one hand a breakdown of the old system sufficiently complete to allow of the development of a currency of sorts (the shati), and on the other commodity, for example, fish, of which this weight indicated their allowance. It may be asked if this evidence should not be taken to indicate that in earlier times also weights were used for such a purpose. To us it must seem extraordinary that

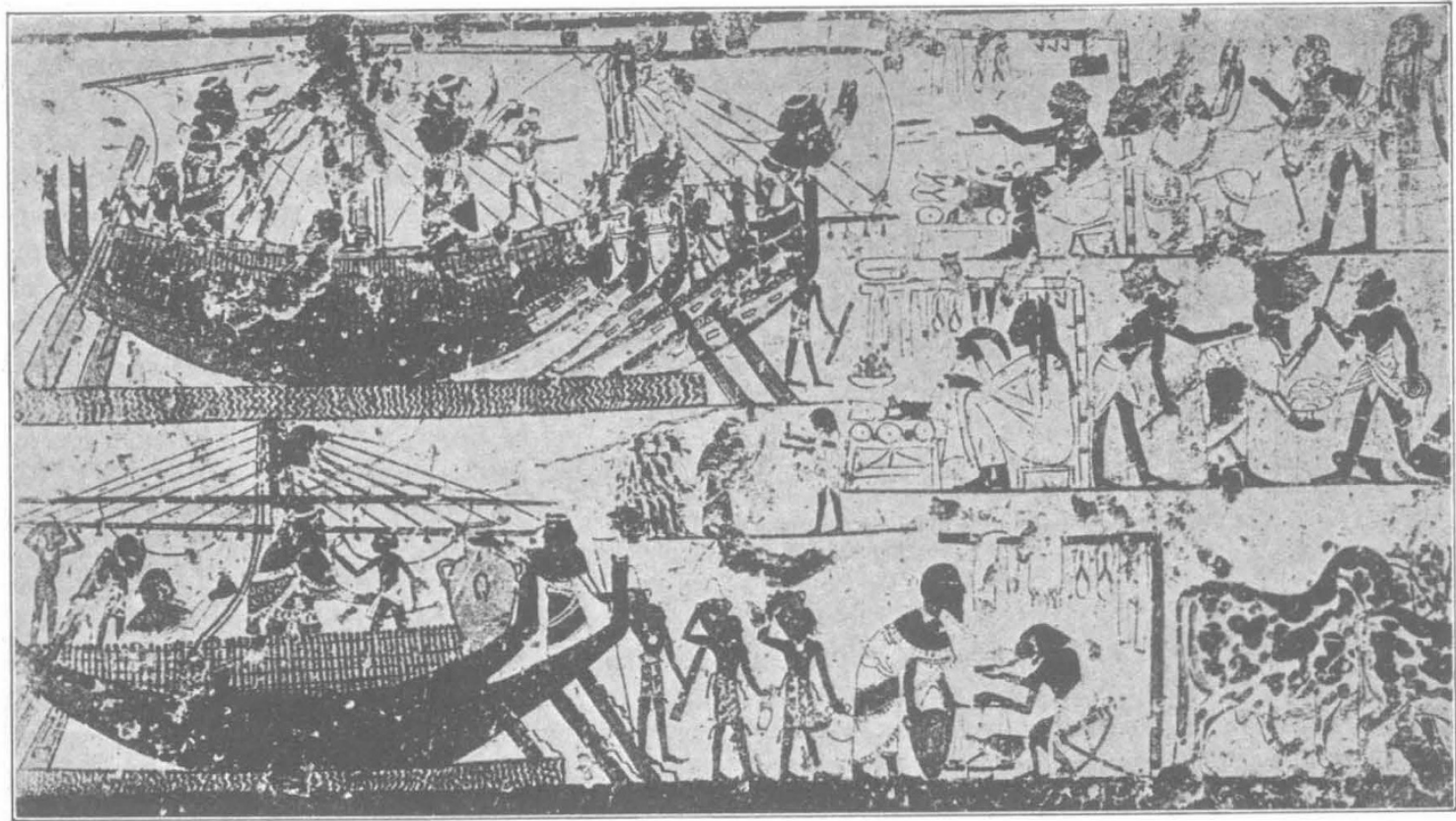

FiG. 4. Egyptian harbour scene: the balance in use for private transactions (c. 1250 B.c.). After a Theban tomb painting.

the essence of the old estate-cum-barter system being used by the Crown as in earliest times in its relations with the workmen employed on its monuments, who receive payment in food and commodities. Weights have been recovered with the names of the workmen and the name of the weights should have been used for more than two thousand years for one purpose only, before they were adapted for the direct weighing of commodities as we use them to-day. Until further information is available, it is unwise to speculate on this point.

\section{The British Association}

\section{A Five-Years' Retrospect, I93I-35}

GIVE-YEARS' PLANS are popular nowadays, and some of their begetters may have cause to remember with a wry smile Johnson's remark to Reynolds that "There are two things which I am confident I can do very well : one is an introduction to any literary work, stating what it is to contain, and how it should be executed in the most perfect manner; the other is a conclusion shewing from various causes why the execution has not been equal to what the authour promised to himself and to the publick".

The British Association has never, so far as we know, committed itself to any grandiose scheme of planning; but with the beginning of its second century, it has adventured upon a new course. As each quinquennium passes, the Association proposes to issue a review of its work-especially that work which arises out of the activities of the annual meeting, and is carried on in the intervals between the meetings. The first number of the series has just appeared.

The descent of two or three thousand members on a town in early September always causes something of a commotion. The livelier dailies blaze out into headlines which tell how a "Woman Scientist Amazes her Male Colleagues"; the sedater journals reflect on the potency of the weapons which science puts into the possession of 